\title{
Psychiatric morbidity and socio-occupational dysfunction in residents of a drug rehabilitation centre: challenges of substance misuse management in a Bruneian context ${ }^{\dagger}$
}

\author{
Hilda Ho, ${ }^{1}$ Anddy Maz Adanan ${ }^{1}$ and Radiah Omar ${ }^{1}$
}

BJPsych Bulletin (2015), 39, 213-217, doi: 10.1192/pb.bp.113.046300

${ }^{1}$ Ministry of Health, Brunei

Correspondence to Hilda Ho (hilda.ho@moh.gov.bn)

First received 26 Nov 2013, final revision 25 Feb 2014, accepted 13 May 2014

(C) 2015 The Authors. This is an openaccess article published by the Royal College of Psychiatrists and distributed under the terms of the Creative Commons Attribution License (http:// creativecommons.org/licenses/by/ 3.0), which permits unrestricted use, distribution, and reproduction in any medium, provided the original work is properly cited.

\begin{abstract}
Aims and method In 2011, a psychiatric clinic was started in Pusat Al-Islah, a drug rehabilitation centre. Our aim was to record self-reported socio-occupational dysfunction and patterns of drug misuse and to evaluate the usefulness of a psychiatric screening tool. A two-phased approach using the Self-Reporting Questionnaire (SRQ) and the Mini International Neuropsychiatric Interview (MINI) was used to examine the rates of psychiatric diagnoses.
\end{abstract}

Results Methamphetamine was the most commonly misused substance in $94.5 \%$ of residents. High levels of socio-occupational dysfunction were reported. In total, $5.5 \%$ met criteria for major depressive disorder, $4.8 \%$ for lifetime psychotic disorder and $11.5 \%$ for suicidal ideation. In addition, $13.3 \%$ reported previous untreated mental health problems.

Clinical implications A screening tool such as the SRQ can be used to identify those needing further psychiatric assessment. Interventions to address amphetamine misuse and associated socio-occupational dysfunction are required. Societal views and legislation influence the management of substance misuse problems in Brunei.

Declaration of interest R.O. is a member of the Advisory Committee, Pusat Al-Islah.
Pusat Al-Islah is a residential drug rehabilitation centre run by the Narcotics Control Bureau (NCB) in Brunei, a small country in Southeast Asia. Residents are sent here after being convicted of drug use offences and testing positively for illegal substances. This is a prison diversion scheme that aims to rehabilitate drug misusers and reduce the rates of reoffending by offering a residential rehabilitation programme and post-release supervision. A small number are voluntary admissions. Treatment is based on a therapeutic community model and residents stay for up to 30 months. There is occupational training, Islamic religious lessons and counselling. A general practitioner and primary care nurse provide primary healthcare. In 2011, a psychiatric clinic was started. This was an opportunity to examine psychiatric morbidity among residents. The high prevalence of psychiatric morbidity in correctional and drug-misusing populations has been highlighted elsewhere, but there is no existing data for Brunei. This is a group who can be difficult to engage in treatment. Admission into the centre is an opportunity to screen for and treat any significant illness. Psychiatric morbidity is likely to have an impact on rehabilitation. Those individuals with mental disorders are more vulnerable to the adverse effects of imprisonment and

†See commentary, pp. 218-220 are at higher risk of suicide. ${ }^{1}$ They may have difficulty adhering to rehabilitation programmes. ${ }^{2}$ We hypothesised that there would be a high level of psychiatric morbidity and socio-occupational dysfunction in this population. We also evaluated the usefulness of a psychiatric screening tool. Finally, we consider the challenges facing substance misuse management in the Bruneian context.

\section{Method}

This was a cross-sectional study. Ethical approval was obtained from the Research \& Ethics Committee, Ministry of Health, Brunei Darussalam. Those who were residing in Pusat Al-Islah on 1 January 2012 or admitted by 31 March 2012 were approached to take part in phase 1 of the project after giving written informed consent. The interviews were conducted by three researchers, a consultant forensic psychiatrist (H.H.), a doctor training in psychiatry (A.M.A.), and a senior psychiatric nurse (R.O.).

\section{Phase 1}

All residents were interviewed using the Self-Reporting Questionnaire-24 (SRQ-24) ${ }^{3}$ between January and June 2012. This is a tool that has been shown to have good 
sensitivity and specificity for identifying psychiatric morbidity in primary healthcare settings. ${ }^{3}$ As Malay is the main language spoken in Brunei, we used a Malay language version that has been used to examine psychiatric morbidity in a Malay-speaking population. ${ }^{4}$ Questions $1-20$ relate to neurotic symptoms and questions 21-24 to psychotic symptoms. Those who scored above a cut-off score of 6 and above for the first 20 questions and/or 1 and above for the last 4 questions, were entered into phase 2 of this study. This cut-off has been suggested to have the best 'trade-off' between sensitivity and specificity. Demographic details, educational and employment history, drug misuse history, psychiatric history, self-reported violence and offending history were also obtained. Data regarding socio-occupational function were obtained using an open questioning style. Any participant thought to require clinical assessment was referred to the psychiatric clinic.

\section{Phase 2}

Residents proceeding to phase 2 were interviewed using the Malay version of the Mini International Neuropsychiatric Interview (MINI, version 6.0). ${ }^{5}$ The MINI is a short semistructured diagnostic interview for $\mathrm{DSM}-\mathrm{IV}^{6}$ and ICD $-10^{7}$ psychiatric disorders. It has been shown to have good validity and interrater reliability. ${ }^{5}$ The Malay version has been shown to have good reliability in diagnosing major depressive disorder and generalised anxiety disorder in a Malaysian community setting. ${ }^{8}$ The sections coding for the following groups of disorders were used: major depressive episode, suicidality, manic and hypomanic episodes, psychotic disorders and mood disorder with psychotic features, generalised anxiety disorder. The prevalence of these disorders was the main focus of the study as they are common treatable causes of psychiatric morbidity. All interview records were checked by the consultant forensic psychiatrist (H.H.) for accuracy.

\section{Statistical analyses}

Data were analysed using the Statistical Package for the Social Sciences, SPSS, version 16 for Windows.

\section{Results}

\section{Demographics}

In total, 195 residents were approached to take part and 165 residents (140 (84.8\%) men and 25 (15.2\%) women) consented and were interviewed for phase 1 . Their mean age was 33.1 years (range 18-55, s.d. =7.6). The mean length of stay before the interview was 14.8 months (range 1-33, s.d. $=9.7)$. A total of $155(93.9 \%)$ were admitted under an order of the Courts or the Minister of Home Affairs; 10 (6.1\%) were voluntary admissions. Of participants, 161 (97.6\%) had been born in Brunei; 91 (55.2\%) were married, $95(57.6 \%)$ had children under the age of 18 years and 57 (34.5\%) were unemployed at the time of admission. Well over half, $101(61.2 \%)$ had not completed secondary school. All residents who declined consent were men.

\section{Index offence}

In total, 148 (89.7\%) were admitted for a drug use offence alone, 16 (9.7\%) were admitted for drug dealing in addition to a drug use offence. Data were missing for $1(0.6 \%)$ resident.

\section{Drug misuse history}

The mean age of starting drug misuse was 19.8 years (range $9-46$, s.d. $=7.1$ ). The mean time period from starting drug use to the interview was 13.7 years (range 1-35, s.d.=7.1). Methamphetamines were the most commonly misused substance. The drugs misused are described in Table 1. The majority of residents reported using drugs at least once a week and experienced some physical or psychological discomfort after a period of abstinence (Table 2).

\section{Psychiatric history}

Of participants, 29 (17.6\%) reported previous contact with psychiatric services, $9(5.5 \%)$ residents were taking psychiatric medication (antidepressant, antipsychotic or mood stabiliser). In total, 13 (7.9\%) had previous admissions for psychiatric treatment, $5(3.0 \%)$ had received involuntary treatment under the Lunacy Act. ${ }^{9}$ Twenty-two participants (13.3\%) reported experiencing mental health problems in

\section{Table 1 Type of substance misuse $(n=165)$}

\begin{tabular}{lc} 
Substance misused & $n(\%)$ \\
\hline Crystal methamphetamine & $159(96.4)$ \\
\hline Main drug misused & $152(92.1)$ \\
\hline Other amphetamine/stimulants & $23(13.9)$ \\
\hline Cannabis & $61(37.0)$ \\
\hline Cough medicine & $52(31.5)$ \\
\hline Solvents & $16(9.7)$ \\
\hline 'Pills' & $8(4.8)$ \\
\hline Steroids & $64(38.8)$ \\
\hline Intravenous drug misuse ${ }^{\text {a }}$ & $2(1.2)$ \\
\hline Alcohol problem ${ }^{\text {b }}$ & $102(61.8)$ \\
\hline a. All methamphetamines. \\
problem.
\end{tabular}

Table 2 Frequency of drug misuse, and symptoms after abstinence $(n=165)$

$n(\%)$

\begin{tabular}{lc}
\hline Frequency of drug use & \\
Daily & $72(43.6)$ \\
At least twice a week & $49(29.7)$ \\
Once a week & $16(9.7)$ \\
$1-3$ times a month & $24(14.5)$ \\
Less than once a month & $3(1.8)$
\end{tabular}

Symptoms after abstinence

Experienced physical (shaking, sweating,

sleep disturbance) or psychological

(irritability, craving, anxiety) discomfort 
the past, for which they had not sought treatment. There were 16 (9.7\%) who reported experiencing previous suicidal ideation. In addition, 19 (11.5\%) reported having a first- or second-degree relative with mental health problems. Psychiatric case-notes were found for 26 (15.8\%) residents. When these were examined for recorded diagnoses, 13 (7.9\%) had a psychotic illness (schizophrenia or acute psychotic episode), 9 (5.5\%) had a depression, 1 (0.6\%) had bipolar disorder, $2(1.2 \%)$ had personality disorder and 1 $(0.6 \%)$ had a child and adolescent mental disorder, unspecified. A total of $13(7.9 \%)$ were recorded to have been non-adherent with treatment. Also, 9 (5.5\%) participants had previous self-harm documented.

\section{Forensic history}

In total, $28(17.0 \%)$ had previous admissions to Pusat Al-Islah; 61 (37.0\%) had served at least one prison sentence; $20(12.1 \%)$ had been convicted of an previous offence without a prison sentence, 39 (23.6\%) had been remanded by the police but released without charge or conviction. Also, 41 (24.8\%) reported performing previous physical violence such as assault.

\section{Socio-occupational function}

Of all the participants, 75 (45.5\%) reported problems with their educational or work performance attributed to drug misuse. A total of 68 (41.2\%) reported financial problems, 98 (59.4\%) reported family relationship problems and 22 (23.2\% of those with children $<18$ years old) reported having difficulty caring for their children adequately. Sixty participants $(36.4 \%)$ reported offending behaviour related to their drug misuse. Also, 77 (46.7\%) had a first-degree relative (parent, child or sibling) who misused drugs and 14 (8.5\%) had a spouse or partner who misused drugs.

\section{SRQ scores}

The mean score for questions 1-20 was 3.6 (range 0-18, s.d. $=3.9$ ) and for questions 21-24 was 0.25 (range $0-3$, s.d. $=0.7)$. A total of $40(24.2 \%)$ residents, 31 men and 9 women, met criteria for entry into phase 2 . When means were compared using the independent $t$-test, no significant differences were found between the phase 1 and phase 2 groups for age (32.2 v. 33.4 years, $P=0.386)$, duration of drug misuse problem (13.75 v. 13.5 years, $P=0.458)$ and age of starting drug misuse (20.1 v. 18.9 years, $P=0.357$ ).

\section{Phase 2}

Interviews occurred after phase 1 was completed, between August and October 2012. Of the 40 residents who were eligible for entry into phase 2, 10 residents had been discharged and were invited for interview, however, 7 discharged residents did not respond to the invitation for a second interview, 1 resident was not cooperative. Therefore, 32 participants (23 men (71.9\%) and 9 women (28.1\%)) were interviewed.

In total nine (5.5\%) met criteria for major depressive disorder (two 'current', six 'previous' and one 'current and previous') of whom three $(1.8 \%)$ met criteria for major depressive disorder with psychotic features ('current', 'previous' or 'current and previous'). Three (1.8\%) participants met criteria for previous manic episode, three (1.8\%) met criteria for hypomanic episode ('current' or 'previous') and six (3.6\%) met criteria for previous hypomanic symptoms. There were three (1.8\%) participants who met criteria for bipolar I disorder ('current' or 'previous'), three (1.8\%) met criteria for bipolar II disorder ('previous or current and previous') and five (3.0\%) met criteria for 'uncategorised bipolar disorder'. Eight (4.8\%) met criteria for lifetime psychotic disorder, of whom five (3.0\%) met criteria for current psychotic disorder. There was one individual (0.6\%) who met criteria for current generalised anxiety disorder. A total of 19 (11.5\%) met criteria for suicidal ideation (15 at 'low level', 1 'medium level' and 3 'high level') (Table 3). Eight (4.8\%) had more than one diagnosis.

\section{Discussion}

\section{Screening and diagnostic tools}

The SRQ is easy and quick to use. The interviewers found that questions 1-20, which asked about depressive and neurotic symptoms, were more easily understood than questions 21-24, which asked about psychotic symptoms. In particular, question 22 referring to grandiosity was often misunderstood. It was concluded that the first 20 questions would be a useful screening tool for depressive and neurotic disorders, whereas the psychosis questions should be amended. Of the 40 residents who entered phase 2,24 (60\%) were found to have a diagnosis and/or suicidal ideation when interviewed with the MINI. Thus, this method of identifying patients with psychiatric disturbance appeared to have produced a high 'yield'. The MINI, although straightforward to use as a diagnostic tool was time-consuming to administer. We concluded that the SRQ could be used to screen residents on admission, and those scoring above the cut-off referred for further assessment.

\begin{tabular}{|c|c|}
\hline $\begin{array}{l}\text { Mini International Neuropsychiatric Interview } \\
\text { (MINI) diagnosis }\end{array}$ & $n(\%)$ \\
\hline Major depressive disorder & $9(5.5)$ \\
\hline Major depressive disorder with psychotic features & $3(1.8)$ \\
\hline Manic episode & $3(1.8)$ \\
\hline Hypomanic episode & $3(1.8)$ \\
\hline Hypomanic symptoms & $6(3.6)$ \\
\hline Bipolar I disorder & $3(1.8)$ \\
\hline Bipolar II disorder & $3(1.8)$ \\
\hline Uncategorised bipolar disorder & $5(3.0)$ \\
\hline Lifetime psychotic disorder & $8(4.8)$ \\
\hline Current psychotic disorder & $5(3.0)$ \\
\hline Current generalised anxiety disorder & $1(0.6)$ \\
\hline Suicidal ideation & $19(11.5)$ \\
\hline$>1$ diagnosis & $8(4.8)$ \\
\hline
\end{tabular}




\section{Rates of mental disorders}

Although the high prevalence of psychiatric morbidity in correctional populations has often been highlighted in Western countries, ${ }^{10-13}$ there is less data available in nonWestern countries. ${ }^{14}$ High prevalence of mental disorders have been found in an Iranian prison population. ${ }^{15}$ Similarly, high rates of psychiatric morbidity were found in individuals who misused methamphetamine detained in Taiwan. ${ }^{16}$ This is the first investigation of psychiatric morbidity in a drug-misusing population in Brunei. Major depressive disorder was the most common diagnosis and was observed in $5.5 \%$ of the sample, similar to the Taiwanese finding. Lifetime psychotic disorder was found in $4.8 \%$ of residents, $3.0 \%$ of whom had a current psychotic disorder. Although we attempted to exclude psychotic symptoms directly associated with substance misuse, it is possible that some findings may have been methamphetamine psychosis rather than a primary psychotic disorder. Bipolar I disorder was observed in $1.8 \%$ of residents and bipolar II disorder was similarly observed in $1.8 \%$ of residents. The rates of psychotic ${ }^{17}$ and bipolar disorders ${ }^{18}$ appeared to be higher than in the general population, although no epidemiological data exist for the prevalence of mental disorders in Brunei.

\section{Previous psychiatric disturbance and socio-occupational dysfunction}

We found substantial rates of psychiatric morbidity. Our results also indicate substantial socio-occupational dysfunction, violence and offending behaviour. Given that these were self-reported, it is likely that they were underestimated. These findings emphasise the need for psychiatric, psychological, behavioural and socio-occupational interventions.

\section{Pattern of drug misuse}

Crystal methamphetamine is commonly available in Southeast Asia. It is locally known as 'syabu' and was the most common drug of misuse found in this sample. The first case of crystal methamphetamine misuse was reported to the NCB in 1993. Since then its use has spread across the country, affecting many lives and families. Drug supplies are manufactured abroad and transported across the border from neighbouring countries, often by land or water routes. Southeast Asia has a higher consumption of amphetaminetype substances compared with the global average. The neighbouring countries of Thailand, Malaysia, Cambodia and Indonesia have seized record high amounts of crystalline methamphetamine in the past few years. Annually, hundreds of illicit synthetic drug manufacturing facilities have been seized in the region over the same period. ${ }^{19}$ The availability of crystal methamphetamine is likely to contribute significantly to its popularity in Brunei. In contrast, the country has not had a widespread heroin misuse problem, avoiding the hazards associated with intravenous drug misuse. This pattern of drug misuse should inform national drug treatment and rehabilitation strategies. Substitute prescription such as methadone programmes used to treat heroin addiction more common elsewhere, cannot be usefully applied here.

We found that the rate of self-reported alcohol problems in this population was very high (61.8\%). This may reflect the conservative Islamic view regarding alcohol use in Brunei, which may lower the threshold for viewing alcohol consumption as problematic and increase the likelihood of problems associated with its use.

\section{Societal views of drug and alcohol use}

Societal views regarding drug and alcohol use are generally very conservative. This is reflected in the heavy penalties imposed on those convicted of drug misuse, dealing and trafficking offences. ${ }^{20}$ More than two-thirds of the population is Muslim and it is the official religion of the state. It is expected that alcohol should not be consumed at all by Muslims. The sale of alcohol is banned, and only non-Muslim adults are allowed to take controlled quantities into the country for personal use. Public drinking is not allowed. The phased introduction of the Syariah Penal Code, ${ }^{21}$ which began in April 2014, further increases the prospects of heavy punishment for those who contravene the strict laws relating to alcohol use. Under this new law, drinking alcohol is an offence for Muslims. Public drinking both in the country and abroad, providing alcohol to a Muslim and abetment of a Muslim to consume alcohol are listed as punishable offences for non-Muslims. Those convicted of alcohol offences may be fined, imprisoned and punished with whipping.

\section{Treatment for alcohol and drug misuse}

Many people are reluctant to admit their problems or seek help, although individuals can present themselves to psychiatric services. Pharmaceutical preparations such as disulfiram and naltrexone are available for the treatment of alcohol misuse. Structured community alcohol or drug misuse treatment programmes run either by medical services or the voluntary sector, are not available. There is limited open discussion about drug and alcohol misuse problems. The cause and impact of these problems locally and treatment and rehabilitation are areas that have received little research attention. Rehabilitation in Pusat Al-Islah, similar to other rehabilitation and training schemes in the country, places a strong emphasis on Islamic religious counselling. Psychological and behavioural treatment programmes require much development.

Our clinical experience working in psychiatric treatment facilities suggest that many individuals with substance misuse problems also have mental health problems requiring multidisciplinary care. The government provides largely hospital-based psychiatric services. Community, subspecialist and multidisciplinary services are limited although there have been some recent developments. New mental health legislation, in the form of the Mental Health Order 2014, has been approved. This legislation is designed to ensure the appropriate care of people with mental disorders and is scheduled to be implemented on 1 November 2014. The development of multisector partnerships is crucial to fully addressing the complex needs of this population. 


\section{Limitations}

The two-phase design of this study may have reduced the accuracy of the results. Residents with a current diagnosis in phase 1 may have recovered before the phase 2 interview. However, the MINI allows for previous and lifetime diagnoses to be coded. The Malay translations of both tools may have limited validity in this population as the Malay dialect spoken in Brunei is slightly different to standard written Malay. The MINI interviewers were not masked to the diagnoses or treatment received by participants. This study depended on self-reporting of socio-occupational dysfunction as we were unable to obtain official reports. It is likely that the true prevalence of psychiatric disorders and socio-occupational dysfunction were higher given the limitations. The sample size in this study was small, with only 32 patients being finally assessed in phase 2. This may have affected the accuracy of our findings. We suggest that any future study should screen a larger sample of new residents on admission, with the diagnostic interview conducted as soon as individuals with mental disorders are identified. This would measure the incidence rates of mental disorders more accurately.

In conclusion, this is the first study to examine psychiatric morbidity, pattern of drug misuse and socio-occupational dysfunction in a Bruneian population of drug misusers. It highlights the treatment and intervention needs of this high-risk group and the challenges faced locally.

\section{Funding}

This study was funded by the Ministry of Health.

\section{Acknowledgements}

We thank the staff of Pusat Al-Islah and the NCB for their assistance. We thank David V. Sheehan and Christopher Gray of Medical Outcome Systems for their permission to use the MINI.

\section{About the authors}

Hilda $\mathrm{Ho}$ is a consultant forensic psychiatrist and head of psychiatric services with the Ministry of Health, Brunei. Anddy Maz Adanan is a medical officer with the Ministry of Health, Brunei. Radiah Omar is a senior nursing officer with the Ministry of Health, Brunei.

\section{References}

1 Dooley E. Prison suicide in England and Wales, 1972-1987. Br J Psychiatry 1990; 156: 40-5.

2 Brady TM, Krebs CP, Laird G. Psychiatric comorbidity and not completing jail-based substance abuse treatment. Am J Addict 2004; 13: 83-101.
3 Harding TW, Arango MV, Baltazar J, Climent CE, Ibrahim HHA, Ignacio $\mathrm{LL}$, et al. Mental disorders in primary health care: a study of their frequency and diagnosis in four developing countries. Psychol Med 1990; 10: $231-41$.

4 Salleh MR. Psychiatric morbidity in schizophrenic relatives - use of the Self-Reporting Questionnaires (SRQ). Singapore Med J 1990; 31: 457-62.

5 Sheehan DV, Lecrubier $\mathrm{Y}$, Sheehan $\mathrm{KH}$, Amorium $\mathrm{P}$, Janavs J, Weiller $\mathrm{E}$, et al. The Mini-International Neuropsychiatric Interview (M.I.N.I): The development and validation of a structured diagnostic psychiatric interview for DSM-IV and ICD-10. J Clin Psychiatry 1998; 59 (suppl 20): 22-33.

6 American Psychiatric Association. Diagnostic and Statistical Manual of Mental Disorder (4th edn) (DSM-IV). APA, 1994.

7 World Health Organization. The ICD-10 Classification of Mental and Behavioural Disorders: Clinical Descriptions and Diagnostic Guidelines. WHO, 1992.

8 Mukhtar F, Abu Bakar AK, Mat Junus M, Awaludin A, Abdul Aziz S, Midin $M$, et al. A preliminary study on the specificity and sensitivity values and inter-rater reliability of Mini International Neuropsychiatric Interview (MINI) in Malaysia. ASEAN J Psychiatry 2012; 13: 157-64.

9 Laws of Brunei. Lunacy Act. Laws of Brunei,1929 (http:// www.agc.gov.bn/agc1/images/LAWS/ACT_PDF/cap048.pdf).

10 Birmingham L. The mental health of prisoners. Adv Psychiatr Treat 2003; 9: 191-201.

11 Gunter TD, Arndt S, Wenman G, Allen J, Loveless P, Sieleni B, et al. Frequency of mental and addictive disorders among 320 men and women entering the lowa prison system: use of the MINI-Plus. J Am Acad Psychiatry Law 2008; 36: 27-34.

12 Sirdifield C, Gojkovic D, Brooker C, Ferriter M. A systematic review of research on the epidemiology of mental health disorders in prison populations: a summary of findings. J Forensic Psychiatry 2009; 20 (S1): S78-101.

13 Fazel S, Danesh J. Serious mental disorder in 23000 prisoners: a systematic review of 62 surveys. Lancet 2002; 359: 545-50.

14 Fazel S, Lubbe S. Prevalence and characteristics of mental disorders in jails and prisons. Curr Opin Psychiatry 2005; 18: 550-4.

15 Assadi SM, Noroozian M, Pakravannejad M, Yahyazadeh O, Aghayan S, Shariat SV, et al. Psychiatric morbidity among sentenced prisoners: prevalence study in Iran. Br J Psychiatry 2006; 188: 159-64.

16 Lin SK, Ball D, Hsiao CC, Chiang YL, Ree SC, Chen CK. Psychiatric comorbidity and gender differences of persons incarcerated for methamphetamine abuse in Taiwan. Psychiatry Clin Neurosci 2004; 58: 206-12.

17 Andrews G, Henderson S, Hall W. Prevalence, comorbidity, disability and service utilization. Overview of the Australian National Mental Health Survey. Br J Psychiatry 2001; 178: 145-53.

18 Merikangas KR, Jin R, He JP, Kessler RC, Lee S, Sampson NA et al. Prevalence and correlates of bipolar spectrum disorder in the world mental health survey initiative. Arch Gen Psychiatry 2011; 68: 241-51.

19 United Nations Office on Drugs and Crime. World Drug Report. UNODC, 2013 (http://www.unodc.org/unodc/secured/wdr/wdr2013/ World_Drug_Report_2013.pdf).

20 Laws of Brunei. Misuse of Drugs Act. Laws of Brunei, 1978 (http:// www.agc.gov.bn/agc1/images/LAWS/ACT_PDF/cap027.pdf).

21 Laws of Brunei. Syariah Penal Code. Laws of Brunei, 2013 (http:// www.agc.gov.bn/agc1/images/LAWS/Gazette_PDF/2013/EN/ syariah\%20penal\%20code\%20order2013.pdf). 